\title{
Digital Technology Implementation for Smart City and Smart Port Cooperation
}

\author{
Igor Ilin \\ Graduate School of Business and \\ Management \\ Peter the Great St.Petersburg \\ Polytechnic University \\ Saint Petersburg, Russia \\ ivi2475@gmail.com \\ Sofia Kalyazina \\ Graduate School of Business and \\ Management \\ Peter the Great St.Petersburg \\ Polytechnic University \\ Saint Petersburg, Russia \\ kaliazina.s@gmail.com
}

\author{
Carlos Jahn \\ Instiute of Maritime Logistics \\ Hamburg University of Technology \\ Hamburg, Germany \\ carlos.jahn@tuhh.de
}

\author{
Jürgen Weigell \\ Instiute of Maritime Logistics \\ Hamburg University of Technology \\ Hamburg, Germany \\ uergen.weigell@tuhh.de
}

\begin{abstract}
A promising direction for the development of society, especially in the conditions of the industry 4.0 paradigm, a of is the Smart City. The purpose of the Smart City is to optimize resources, monitor security, and maximize the level of services for the population. For the successful development of the concept of the Smart City, the integration of various systems and technologies is required. One part of the Smart City concept in particular to consider is the Smart Port. This article examines the existing digital solutions for the automation of Smart Ports, the direction of technology development, the existing problems and prospects for the digitalization of port terminals and transport logistics operators.
\end{abstract}

Keywords-Smart City, Smart Port, digitalization, Internet of Things, artificial intelligence, logistics.

\section{INTRODUCTION}

Modern economic conditions are characterized by the globalization, the grow increasing rates of growth in international trade, and the development of technologies in the Industry 4.0 paradigm. One of the most popular areas of development is the concept of the Smart City. It The Smart City is an interconnected system of communication and information technologies with the Internet of things (IoT), which simplifies the management of internal processes of the city and improves the standard of living. "A Smart City is settled area which utilizes systemic (in terms of ecological. Social and economic aspects) and sustainable products, services, technologies, processes and infrastructures, in most cases supported by highly integrated and networked information and communication technologies"[1].

It is expected that the introduction of information technologies and IoT facilities in the urban environment will improve the system of management and interaction of the state government, society, business representatives, as well as the quality and efficiency of all processes in the city. The main asset of the city will be people, processes and technologies $[2,3]$.
In a Smart City, it is desirable to have a Smart Port as one of the components. The Smart Port is more competitive, addressing the challenges of managing customers and cargo flow. The globalization of freight traffic, the development of the world economy and international trade require more and more complex schemes for cargo delivery and cost optimization during transportation and storage of goods, determining the growing demand for comprehensive transport and logistics services. Seaports are focused on the integration of automated system solutions. IoT, cloud computing and the ubiquitous availability of networks enable digital transformation of seaports around the world. Digital applications can play a major role in a large number of port operations and shipping: from logistics management to improving cargo operations. In the Smart Port, decisions can be made based on data analysis and applications for IoT [4]. With the help of the IoT, ports can integrate and share maritime information in a secure environment. In combination with reliable communications on the high seas and during the land transport, the IoT can significantly increase the efficiency of ports in areas such as automated data processing.

There is also the concept of "Smart Logistics", which is derived from a technology driven approach [5]. Smart Logistics is a core element of Industry 4.0 [6]. Hermann et al. define four necessary parts of Industry 4.0. These are connectivity, decentralized decisions, transparent information, and technical assistance [7]. Smart logistics is based on lean and intelligent supply chains, agile cooperation networks and an organizational network [6].

International logistics operators (transport companies) have the task to provide a personalized response to customer needs. Accordingly, it is necessary to use all the possibilities of digitalization in logistics and automation of supply chains and consider new opportunities for building supply chains on an international scale [8,9]. This work must be synchronized with the creation of a value chain from the production of the goods to the delivery to the final consumer. This approach expands the scope of the logistics operator to other related 
business areas. One aspect is the automation of container shipping.

\section{EXISTING DIGITAL TECHNOLOGIES FOR SMART PORT}

As an example of the possibilities of using digital technologies and automation, the article will consider shipping and port logistics. The competitiveness of seaports can be determined by the ability to comprehensively meet customer requirements for the characteristics of logistics processes within supply chains, retain existing freight traffic, and also win new ones, competing in both domestic and foreign markets due to the qualitative improvement of the provided logistics services [10]. Containerization plays a special role in the development of ports, the entire transport infrastructure, international trade and logistics. Containers are an intermodal tool that allows intermodal transport chains to function. Their efficient organization reduces transportation costs. The development of the port's logistics infrastructure and the range of services provided are closely related to the planning of production and logistics processes in the supply chains of industrial and trading companies by improving of the efficiency of port the overall efficiency of the supply chain will be increased [10]. Logistics and SCM approaches are often implemented in terms of lean (lean manufacturing) and agile processes, where the former focus on cost-effectiveness and long-term forecasts, while the latter focus on quick response to customer requests and short lead times. Modern logistics enterprises are suffering huge losses due to empty runs. Moreover, additional pollution is associated with this. A unified information system across the value chain helps reduce transaction costs in the supply chain, diversify the business and ensure a high level of customer loyalty.

Taking into account the growing traffic volume, a modern port should ensure high performance, reliability and efficiency of cargo handling, reduction of the vessel's berthing time in the port and uninterrupted operation. This requires changes in the organization of logistics and the use of modern digital technologies.

In the framework of the concept of digitalization and the transition to the concept of "Smart Port", such technologies as driverless cars, IoT, low cost sensor technologies, big data, augmented reality, self-driving vehicles [8], robots and 3D printing (fig. 1).

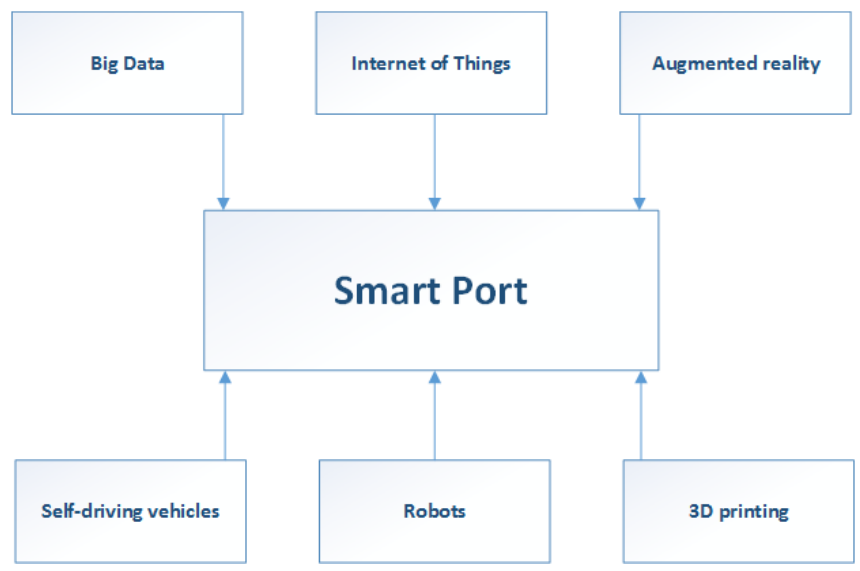

Fig. 1. Key technologies related to the Smart Port concept.

There is experience in the use of unmanned vehicles for the transport of containers between the quay and the storage areas [11]. Routing is provided by transponders installed in the ground. IoT sensors allow monitoring of the containers and the status of their contents in real time. Moreover, they can control events such as falls, breaks and vibrations, as well as temperature, humidity and pressure. IoT in logistics is used in the "Smart Container" in the computing and communication architecture of Edge Computing. For short distances, Wi-Fi, ZigBee, Bluetooth Mesh are used for communication [12]. Advances in IoT sensors and communications allow tracking the conditions for each package in a container. The use of these communication technologies is being developed over long distances, in areas with low cellular coverage, and so on. "Smart tags" solution is also used, which allows monitoring information such as location, shock, vibration, tilt, breakage, temperature, pressure, and humidity [13].

The IoT ecosystem uses a set of industry-specific APIs (Application Programming Interface) "IoTivity", that simplify the integration of logistics systems with other enterprises or work components. Open source software provides a deviceto-device connection regardless of the operating system, service provider, transport technology, ecosystem. Due to this, among other things paperless processes develop. In this context, there are interesting projects on the use of Blockchain for the digitalization of logistics, Smart Port, Smart City [14]. Blockchain, when properly applied, provides security, transparency and decentralization of processes.

Currently, simulation modeling of the port terminal is being used at levels associated with the movement of ships, with the handling of ships on the terminal quay, and with the handling of containers at the terminal. This allows optimizing the use of terminal resources, improving its performance. Reducing the time spent by the vessel in the port, among other things, reduces the impact on the environment. For Smart Warehouses, tagging is widely implemented using low-cost identification devices, such as RFID. Sensors and actuators in combination with radar or cameras attached to forklift trucks can ensure the functioning of self-driving warehouse forklifts [15]. Further in the article we will consider several specific examples of the application of such technologies in various port complexes.

For example, in Italy, work is underway on the Smart Tunnel project, the goal of which is to create a platform for the automation of logistics services in order to increase their efficiency [16]. This work involves the modeling of business processes, communication flows in logistics processes. Automation is based on the open PCS (Port Community Systems) electronic platform, which is operated by various maritime port organizations and ensures the secure exchange of information, electronic document management, standardization, and simplification of procedures [17]. This in itself contributes to the automation of logistics processes and increase the competitiveness of the port. The communication system covers the entire logistics life cycle, starting with the flow planning and storage of goods, through monitoring and control of logistics processes along the supply chain and the conclusion with the delivery of goods to the buyer. The effectiveness of supply chain management depends on the quality and timeliness of the data available in the system. Workflow Management Systems and Enterprise Service Bus software applications enable to provide the interoperability of business processes and the integration of legacy systems. The chain of logistics is supported by the integration of 
information technologies (IT) and innovative communication systems. For example, a container depot management support system (CDMSS) using RFID and mobile commerce (mcommerce) technologies is used [18]. CDMSS consists of account management, container management, transaction management, monitoring and data analysis modules.

The port of Shanghai uses a specially developed information system. Laptops on the pier take a detailed plan of operations from the computer system. Monitors in the operator cabs of cranes, trucks, and gantry cranes communicate with the control center to determine which container moves in which direction. Specialized trucks receive orders from a computer terminal in the control center via wireless routers. This provides an extremely low probability of error and loss of the container [16].

The port of Hamburg is starting a new project, the smartPort. This project is matching economic and ecological aspects in the following three sub-sectors: traffic flows, infrastructure and the flow of goods. This is done by a variety of improvements. For example the use of sensors on the harbor railway which transmit data to a central IT system, by using shore power generated by renewable sources to supply vessels from the landside with power, a cloud based virtual depot for empty containers to optimize the allocation of these containers and the use of the Port monitor software so the stakeholders in the port can access up-to-date data on vessel positions, water level, current construction sites [19]. The port community system (PCS) is operated by DAKOSY and is used by more than 2,000 companies to perform their transport flows. This PCS is one of the most advanced port IT systems in the world. For example processes regarding importing and exporting of goods, custom handling, the management of hazardous goods and managing the arrival and departure of vessels are coordinated using the PCS [20].

The port of Rotterdam uses the Port Forward platform, which additionally offers digital solutions for shippers, freight forwarders and traders who want to increase their understanding of all the complexity of logistics chains and control them. The intelligent route planner displays all options for the possible transportation of cargo from the coast to the interior of the post-cargo handling. The Portmaster tool for safe and efficient port operation provides real-time information from multiple sources of information and port users for optimal planning, monitoring and administration of the facility in a single system. For example, the captain of the vessel, knowing the absence of free piers, may decide to enter the port at another time. In this way, he can avoid the idleness of a vessel in the port, which leads to financial losses for the shipowner. In turn, the port dispatchers see how many ships are on the way to the piers and what decision should be taken with regard to loading and unloading equipment and loading of warehouses. This increases the speed of decision making and improves the quality of port services. Portmaster is based on the latest technologies using Big Data and artificial intelligence [21].

Also, for example, in the field of port logistics, the STORD solution is used, which provides affordable, efficient warehousing and cargo delivery. The technological solution is used to integrate a network of independent third-party warehouses in which customers' cargo is located and processed. The software in the format of a single information panel helps customers manage the flow of goods in several warehouses, which allows to significantly reduce storage costs [22].

\section{PROBLEMS AND OUTLOOKS}

To ensure the digitalization of logistics and the functioning of the Smart Port, a logistic digital infrastructure is needed. The key elements of this infrastructure are: dedicated logistic web services that collect, display and distribute transportation requests; adaptive planners, individually provided to logistics companies and organizations as web-based services; The Internet of Things IoT, which provides communication with logistic resources, including communication between customers, orders, trucks, trains, ships, sections of routes and filling points $[23,24]$.

There is great potential to ensure the coordinated operation of logistics companies without any centralization, which seems impossible, given the complexity of the market. A positive example is shared networks, which allow not to miss a client, even with the possible loss of a part of the profits. Thus, the development of a worldwide distributed digital logistics infrastructure is expected, which will be used by logistics firms to not only compete, but also to cooperate with each other.

Among the nearest digital changes that are obvious to market participants and which are constantly being mentioned at the sites of specialized events, the main ones are highlighted:

- automatic collection of data on the location of the goods and environmental characteristics (for specific goods);

- automatic analyzer of data on loading / release of transport on the route;

- a platform for analyzing the best rates for shipments, also for multimodal shipments;

- solutions to increase the transparency of the activities of all participants in the transport process and the reliability of the workflow.

To implement a digitalization program, companies need:

- Investments in IT solutions.

- Reorganization of internal activities in accordance with the rules of the digital world, retraining of specialists.

For large companies, the following steps are advisable for a gradual transition to digital technology:

- Switch the attention of business owners to digital solutions to optimize business processes, reduce operating costs, improve the efficiency of the company.

- Search for developers for the specific needs of companies that will solve everyday routine processes.

- Monitoring of world solutions, search for bottlenecks in the company, subsequent automation and robotization with the use of artificial intelligence. 
Small companies are encouraged to use cooperation opportunities with partners to create ecosystems in which all participants will be able to optimize their business processes, as well as to look for optimal market solutions taking into account global trends.

Digital transformation will allow companies to increase the customer base and transparency of the activities of transportation participants, better and faster determine transportation prices and make correct and quick decisions on sales, which ultimately increase the profits of companies.

The main directions of digitalization's development in the industry can be considered as simplification and bringing to a new level of workflow, the IoT and artificial intelligence.

\section{CONCLUSION}

The concept of a Smart City, which includes, among other things, smart transport is certainly a promising direction of urban development, which will ensure the safety of residents, optimal use of resources and rational management of the city [25]. For the Smart City and, in particular, for the Smart Port in this city, innovation is a means of development. There are examples of the successful implementation of digital technologies in the world's leading advanced ports. These solutions provide a significant improvement in port terminal performance and customer satisfaction. Such solutions cover not only the port terminal itself, but also the activities of transport logistics operators. For the remaining ports, the introduction of the digital technologies discussed in the article is certainly expedient. Work should begin with the improvement of electronic document management, the use of the IoT and artificial intelligence. All this will ensure the improvement of the quality of the post and its competitiveness.

\section{ACKNOWLEDGMENT}

The reported study was funded by RSCF according to the research project № 19-18-00452.

\section{REFERENCES}

[1] DIN - Deutsches Insitut für Normung e.V. [Electronic source] // URL: https://www.din.de/en/innovation-and-research/smart-cities-en

[2] Berntzen, Lasse \& Johannessen, Marius. (2016). The Role of Citizens in "Smart Cities ".

[3] Bednarska-Olejniczak, D., Olejniczak, J., \& Svobodová, L. (2019). Towards a Smart and Sustainable City with the Involvement of Public Participation-The Case of Wroclaw. Sustainability, 11(2), 332.

[4] A.I. Levina, A.S. Dubgorn, O.Y. Iliashenko, "Internet of things within the service architecture of intelligent transport systems" Proceedings 2017 European Conference on Electrical Engineering and Computer Science, EECS 2017, pp. 351-355.

[5] Uckelmann, D. (2008, September). A definition approach to smart logistics. In International Conference on Next Generation Wired/Wireless Networking (pp. 273-284). Springer, Berlin, Heidelberg.
[6] Zsifkovits, H. \& Woschank, M. „Smart Logistics Technologiekonzepte und Potenziale“. In: BHM Berg- und Huettenmaennische Monatshefte (2019) 164: 42

[7] Hermann, M., Pentek, T., Otto, B., "Design Principles for Industrie 4.0 Scenarios", in Bui, T. X.; Sprague R. H. (eds.): Proceedings of the 49th Annual Hawaii International Conference on System Sciences, Kauai, Hawaii, 2016, Piscataway: IEEE, 2016, S. 3928-3937.

[8] P. H. Tseng, C. H. Liao, "Supply chain integration, information technology, market orientation and firm performance in container shipping firms". The International Journal of Logistics Management, 26(1), 2015, pp. 82-106

[9] K. R. Ahn, S. Y. Lee, "Logistics service model for sustainability of supply chain". Information (An International Interdisciplinary Journal), 17(9), 2014

[10] Verbilo, O. M. (2012). Tendentsii v logistike, vliyayushchiye na konkurentosposobnost' portov. Nauchno-analiticheskiy zhurnal «logistika i upravleniye tsepyami postavok, (4), 51.

[11] Self-Driving Vehicles in Logistics. A DHL perspective on implications and use cases for the logistics industry. DHL 2014

[12] Kupriyanovskiy, V. P., Alen'kov, V. V., Pershin, A. V., Namiot, D. Ye., Klimov, A. A., Volokitin, YU. I., \& Sinyagov, S. A. (2018). Umnyye monogoroda, kak zony ekonomicheskogo razvitiya tsifrovoy ekonomiki. International Journal of Open Information Technologies, 6(1).

[13] Cost-Effective Solution for End-to-End Supply Chain Visibility. Intel IoT Technology Logistics and Asset Management Solutions. Intel 2017.

[14] Czachorowski, Karen \& Solesvik, Marina \& Kondratenko, Yuriy. (2019). The Application of Blockchain Technology in the Maritime Industry. 10.1007/978-3-030-00253-4_24

[15] H. J. Carlo, I. F. Vis, K. J. Roodbergen, "Storage yard operations in container terminals: Literature overview, trends, and research directions." European journal of operational research, 235(2), 2014, pp. 412-430.

[16] M. Bisogno, G. Nota, A. Saccomanno, A. Tommasetti, "Improving the efficiency of Port Community Systems through integrated information flows of logistic processes", 2015.

[17] G. Janssens " Electronic data intercharge: From its birth to its new role in logistics information systems." 2011.

[18] E. W. Ngai, T. E. Cheng, S. Au, K. H. Lai, "Mobile commerce integrated with RFID technology in a container depot." Decision Support Systems, 43(1), 2007, pp. 62-76.

[19] Hamburg Port Authority [Electronic source] // URL: https://www.hamburg-port-authority.de/en/hpa-360/smartport/

[20] DAKOSY [Electronic source] // URL: https://www.dakosy.de/en/solutions/cargo-communications/portcommunity-system/

[21] Port of Rotterdam [Electronic source] // URL: https://www.portofrotterdam.com/en

[22] STORD [Electronic source] // URL: https://www.stord.com/

[23] V. Orlova, I. Ilin, S. Shirokova, "Management of port industrial complex development: Environmental and project dimensions" MATEC Web of Conferences, Vol. 193, 2018

[24] Alesinskaya, T.V., Arutyunova, D.V., Orlova, V.G., Ilin, I.V., Shirokova, S.V. Conception BSC for investment support of port and industrial complexes (2017) Academy of Strategic Management Journal, 16 (Specialissue1), pp. 10-20.

[25] S. Kalyazina, A. Lepekhin, "Implementing an energy harvesting technology within the concept of Smart city". In MATEC Web of Conferences, Vol. 193, p. 01030, 2018. 